\title{
Observational study to correlate BMI with low back pain in young adults
}

\author{
Reddy D.M. ${ }^{1}$, Jagarlamudi P. ${ }^{2}$ \\ ${ }^{1}$ Dr. Madhukrishna Reddy Dandolu, ${ }^{2}$ Dr. Praneeth Jagarlamudi, both authors are affiliated with Department of \\ Orthopaedics, DBR \& SK Super Specialty Hospital, Tirupati, India.
}

Corresponding Author: Dr. D. Madhukrishna Reddy, Department of Orthopaedics, DBR \& SK Super Speciality Hospital, Korlagunta, Tirupati, India. E-Mail: drmadhukrishnareddy@gmail.com

\begin{abstract}
Introduction: Low back pain is a common condition comprising a major health problem worldwide \& will eventually affect almost everyone in life, men and women equally. In the present generation Overweight and obesity a major health hazard and predisposing to major non communicable disease. Young adults between 20-30yrs presenting with low back ache were taken and measured BMI with standard method. Results: In our the study correlation of low back pain in relation to the duration and BMI was analyzed, in which we observed as the BMI increases the duration of LBA also increases. Conclusion: our study the strong association of body mass index in relationship with development of low back ache in young adults of both genders is greatly implicated.
\end{abstract}

Key words: Low back pain, Body mass index, Obesity

\section{Introduction}

Pain over the lower portion of the back below the rib cage is called as low back pain or lumbar back pain. It is a very common medical condition and invariably affects all age groups. Low back pain is caused by injury to a muscle or ligament. Common cause including improper lifting, poor posture, lack of regular exercise, a fracture, a ruptured disc or arthritis. Low back pain is a common condition comprising a major health problem worldwide. It will eventually affect almost everyone in life, men and women equally [1].

The lifetime prevalence of low back pain is estimated at $60 \%$ to $85 \%$, while the annual prevalence in the general population is ranging from $15 \%$ to $45 \%$ [2-4]. The annual incidence of back pain in the general population is estimated between $10 \%$ and $15 \%$ [5]. In the vast majority of patients, low back pain is a self limiting condition, from which $90 \%$ are expected to recover in about 6 weeks [6]. However, high recurrence rates of $40 \%$ to $70 \%$, including annual recurrence rates of $60 \%$, have been reported $[7,8]$. Results from various studies on prevalence, incidence, and recurrence of low back pain are difficult to compare, often because of differences in the period of recall [9]. A complicating

Manuscript Received: $25^{\text {th }}$ April 2019

Reviewed: $4^{\text {th }}$ May 2019

Author Corrected: $10^{\text {th }}$ May 2019

Accepted for Publication: 14 $4^{\text {th }}$ May 2019 factor in low back pain research is the fact that onset and duration of low back pain episodes are difficult to measure. For example, if the time of onset of low back pain is not clearly defined, it is very difficult to distinguish between incidence and recurrence [10]. Obesity is an undesirable outcome of changing in lifestyle and behavior. It is also a major risk factor for development of diabetes, hyperlipidemia and osteoarthritis [11-17].

Obesity may lead to early disability and loss of job in the majority of subjects because of osteoarthritis as well as diabetes and coronary artery associated complications. The medical expense of obesity associated conditions is estimated to be about one hundred million dollars annually in the USA $[18,19]$. Although, the contribution of hereditary factor may account for about $30-70 \%$ of obesity [17], but intake of high caloric diets and reduced expenditure of energy in the form of low physical activities, changing lifestyle and behaviors, particularly, in the modern societies, are also responsible for development of overweight and obesity. The prevalence of obesity varies significantly across the world [20]. The rate of obesity and overweight among adults population ranges from 15 to $60 \%$. It is usually more common in women than men. According to WHO report, obesity has become 


\section{Original Research Article}

epidemic in the world [21]. The main purpose of this observational study among young adults is to estimate the prevalence of chronic low back pain in relation to BMI levels, with adjustment for potential confounders as age, sex, work status, exercise, and tobacco smoking. The target population consisted of all inhabitants aged $20-30$ years.

\section{Methodology}

Type of study and setting: This is an observational study among young adults is to estimate the prevalence of chronic low back pain in relation to BMI levels, in DBR \& SK Super Speciality Hospital, Tirupati which is a 100 bedded multidisciplinary tertiary care centre. Sampling method: 360 subjects including both gender of healthcare provided among the above setting.

Samplecollection: With the consent of the patients all demographic details \& BMI was collected. Inclusion criteria: All patients with age group between 20-30yrs of both genders presented to OPD with low back ache were included in the study. Exclusioncriteria: Patients with secondary cause, trauma, other risk factors (DM, HTN and DYSLIPEMIA) and pregnancy were excluded from the study. Statistical method: The collected data was compiled and statistically analyzed by using SPSS software. The study proposal was approved by the ethical committee of the institution and written informed consent was obtained from all subjects prior to their participation in the study.

Anthropometric measurements and data collectionAfter an interview and clinical examination, the anthropometric measurement of height, weight, waist circumference (WC) was measured by standard method. WC was determined by measuring of waist diameter of the level of midpoint between iliac crest and lower border of tenth rib. The average of three measurements was considered as WC. BMI was measured by standard method. Body mass index (BMI) was calculated by weight in kilogram divided to square of height in meter (kg m).

The demographic and lifestyle data, in particular, age, gender, marital status, marriage age, family history of obesity, educational level, occupation, occupational physical activities, the level of leisure time physical activities, the duration of exercise per week by hours, the number of children and the parity were collected with designed questionnaire. The diagnosis of obesity was confirmed by the WHO standard recommended method $[22,23]$ in which a BMI 25- $29.9 \mathrm{~kg} \mathrm{~m}^{-2}$ was regarded as overweight; $\mathrm{BMI} \geq 30 \mathrm{~kg} \mathrm{~m}^{-2}$ as obesity. Central obesity was diagnosed on the base of WC with cut-off points of $\mathrm{WC}>88 \mathrm{~cm}$ for women and $\mathrm{WC}>$ $102 \mathrm{~cm}$ for men.

\section{Results}

In our study of 180 males and 180 females between 20-30years presented to us with low back ache were enrolled for the study. In our study age group between 27-30 years was more 49\%, among which IT employed were more than $60 \%$. Among the study population more than $90 \%$ do not have travel more than $30 \mathrm{kms}$ in two wheelers. The mean BMI among the study population was $28.06+2.12$ for males and $24.8+3.7$ for females, and the mean height was 174.1 [SD, 6.8] $\mathrm{cm}$ for males and 162.1 [SD, 6.25] $\mathrm{cm}$ for females. Among the study group correlation of low back pain in relation to the duration and BMI was analyzed, in which we observed as the BMI increases the duration of LBA also increases.

Table-1: Gender- wise distribution.

\begin{tabular}{|c|c|c|}
\hline Gender & No. of patients & \% of patients \\
\hline Male & 180 & $50 \%$ \\
\hline Female & 180 & $50 \%$ \\
\hline Total & $\mathbf{3 6 0}$ & $\mathbf{1 0 0 \%}$ \\
\hline
\end{tabular}

Table-2: Age - wise distribution.

\begin{tabular}{|c|c|c|c|}
\hline Age & Male & Female & No of patients \\
\hline $20-22$ & 29 & 19 & 48 \\
\hline $23-24$ & 36 & 41 & 77 \\
\hline $25-26$ & 28 & 30 & 68 \\
\hline $27-28$ & 40 & 40 & 80 \\
\hline $29-30$ & 47 & 50 & 97 \\
\hline Total & $\mathbf{1 8 0}$ & $\mathbf{1 8 0}$ & $\mathbf{3 6 0}$ \\
\hline
\end{tabular}


Table-3: Occupation wise distributions.

\begin{tabular}{|c|c|c|}
\hline Occupation & No of patients & \% of patients \\
\hline IT & 220 & 61.11 \\
\hline Non IT & 140 & 38.88 \\
\hline Total & 360 & $100 \%$ \\
\hline
\end{tabular}

Table-4: Two wheeler ridding.

\begin{tabular}{|c|c|c|}
\hline S.No & $<$ 30km/day & $>$ 30km/day \\
\hline 1 & 330 & 30 \\
\hline
\end{tabular}

Table-5: Body Mass Index.

\begin{tabular}{|c|c|c|c|}
\hline Range & Male & Female & No of patients \\
\hline Below 18.5 & 04 & 07 & 11 \\
\hline $18.5-24.9$ & 42 & 51 & 93 \\
\hline $25-29.9$ & 84 & 73 & 157 \\
\hline 30 -above & 50 & 49 & 99 \\
\hline Central obesity Inappropriate & $09\{\mathrm{WC}[\mathrm{WC}>102 \mathrm{~cm}]\}$ & $13\{\mathrm{WC}[\mathrm{WC}>88 \mathrm{~cm}]\}$ & 22 \\
\hline Total & 180 & 180 & 360 \\
\hline
\end{tabular}

Table-6: LBA duration wise distributions with relation to BMI.

\begin{tabular}{|c|c|c|c|c|}
\hline Duration of LBA & $<$ 1month & $>$ 1 month-6months & $>$ 6month & Total \\
\hline No of persons Both gender & 110 & 168 & 82 & 360 \\
\hline Mean BMI & $22.82+4.44$ & $28.74+1.67$ & $32.63+2.85$ & - \\
\hline
\end{tabular}

\section{Discussion}

The lumbar spine, or low back, is a remarkably wellengineered structure of interconnecting bones, joints, nerves, ligaments, and muscles all working together to provide support, strength, and flexibility. However, this complex structure also leaves the low back susceptible to injury and pain. Depending on the underlying cause of the pain, symptoms can be experienced in a variety of ways.

- Pain that is dull or achy, contained to the low back.

- Stinging, burning pain that moves from the low back to the backs of the thighs, sometimes into the lower legs or feet; can include numbness or tingling (sciatica).

- Muscle spasms and tightness in the low back, pelvis, and hips.

- Pain that worsens after prolonged sitting or standing

- Difficulty standing up straight, walking, or going from standing to sitting
Understanding the complicated nature of low back pain is a daunting challenge. Although low back pain is considered a common and disabling medical condition, its true prevalence throughout life and, in particular, during the first decades of life, is unknown.

There are many causes of pain in the back. Symptoms in the low back can be a result of problems in the bony lumbar spine, discs between the vertebrae, ligaments around the spine and discs, spinal cord and nerves, muscles of the low back, internal organs of the pelvis and abdomen, and the skin covering the lumbar area. Pains in the upper back can also be a result of disorders of the aorta, chest tumors, and inflammation of spine. Common causes of lower back pain include strain injury from athletics or overuse, disc herniation, kidney infection, pinched nerve in the spine, and pregnancy. Less common causes of back pain include infection of the spine, ankylosing spondylitis with lumbosacral and sacroiliac joint disease, compression fracture of a spinal vertebra, disc ligament tear (annular tear), and spinal tumor or cancer in the bone of the spine. 
Two common types of Low Back Pain:

Mechanical pain- By far the most common cause of lower back pain, mechanical pain (axial pain) is pain primarily from the muscles, ligaments, joints (facet joints, sacroiliac joints), or bones in and around the spine.

This type of pain tends to be localized to the lower back, buttocks, and sometimes the top of the legs. It is usually influenced by loading the spine and may feel different based on motion (forward/backward/ twisting), activity, standing, sitting, or resting.

Radicular pain- This type of pain can occur if a spinal nerve root becomes impinged or inflamed. Radicular pain may follow a nerve root pattern or dermatome down into the buttock and/or leg. Its specific sensation is sharp, electric, burning-type pain and can be associated with numbness or weakness (sciatica). It is typically felt on only one side of the body.

Acetaminophen relieves pain in mild arthritis but has no effect on the underlying inflammation, redness, and swelling of the joint. If the pain is not due to inflammation, acetaminophen is as effective as aspirin.

Acetaminophen is as effective as the non-steroidal antiinflammatory drug ibuprofen (Motrin) in relieving the pain of osteoarthritis of the knee. Unless directed by a physician, acetaminophen should not be used for longer than 10 days.

Possible associations of weight and height with low back pain have intrigued researchers for many years. Although low back pain path physiology has been associated with body measures by some experts, there is no consensus on this subject in the literature.

Today, with obesity becoming a rapidly growing problem worldwide, its possible association with the development of low back pain has gained even greater importance.

It has been postulated that, among other serious medical conditions, obesity could explain the concomitantly growing prevalence of low back pain among young adults. Our analysis provides a detailed summary of the prevalence of low back pain in 20-30 years population and pertinent information about its associations with BMI and height. The most intriguing findings of our study are the dose-dependent curves between low back pain and BMI.

\section{Original Research Article}

Here are the lists of studies done at various centers to prove our facts around the world

- HeikkiFrilander et al [22] in his study concluded being overweight or obese in early adulthood as well as during the life course increases the risk of radiating but not non-specific low back pain among men.

- Rahman shiri et al [23] concluded that overweight and obesity increase the risk of low back pain.

- U.K.Ezemagu et al [24] demonstrated the degree of relationship between BMI and LBA.

- Louisa et al [25] also supported our similar results in his study.

- Chowdhury D et al [26] proved the association of LBA and BMI was highly significant.

\section{Conclusion}

In our study the strong association of body mass index in relationship with development of low back ache in young adults of both genders is greatly implicated. Our study also implicates that as BMI increases the duration of LBA also increases. This gives a great importance in the society to overcome overweight and obesity for a healthier society.

\section{Limitations}

- Smaller sample size

- Should be a multicentre study for a better implication.

Conflict of interest: None declared.

Funding: Nil, Permission from IRB: Yes

\section{References}

1. Frymoyer JW. Back pain and sciatica. N Engl J Med. 1988 Feb 4;318(5):291-300. DOI:10.1056/NEJM 198802043180506

2. Anderson GBJ. The epidemiology of spinal disorders. In: Frymoyer JW, ed. The Adult Spine: Principles and Practice, 2nd ed. New York: Raven Press, 1997:93-141.

3. Burton AK, Clarke RD, Mc Clune TD, et al. The natural history of low back pain in adolescents. Spine (Phila Pa 1976). 1996 Oct 15;21(20):2323-8.

4. Deyo RA. Nonsurgical care of low back pain. Neurosurg Clin N Am. 1991 Oct;2(4):851-62.

5. Andersson GB. Epidemiological features of chronic low-back pain. Lancet. 1999 Aug 14;354(9178):581-5. DOI:10.1016/S0140-6736(99)01312-4 


\section{Original Research Article}

6. Waddell G. 1987 Volvo award in clinical sciences. A new clinical model for the treatment of low-back pain. Spine (Phila Pa 1976). 1987 Sep;12(7):632-44.

7. Biering-Sørensen F. A prospective study of low back pain in a general population. I. Occurrence, recurrence and aetiology. Scand J Rehabil Med. 1983;15(2):71-9.

8. Clinical standards Advisory Group. Epidemiology Review: The Epidemiology and Cost of Low Back Pain. London: HMSO, 1994.

9. Biering-Sørensen F, Hilden J. Reproducibility of the history of low-back trouble. Spine (Phila Pa 1976). 1984 Apr;9(3):280-6.

10. Burdorf A, van der Beek A. Exposure assessment strategies for work-related risk factors for musculoskeletal disorders. Scand J Work Environ Health. 1999;25 Suppl 4:25-30.

11. Seidell JC. The impact of obesity on health status: some implications for health care costs. Int J Obes Relat Metab Disord. 1995 Nov;19 Suppl 6:S13-6.

12. Groessl EJ, Kaplan RM, Barrett-Connor E, et al. Body mass index and quality of well-being in a community of older adults. Am J Prev Med. 2004 Feb; $26(2): 126-9$.

13. Ridker PM, Genest J, Libby O. Risk factors for atherosclerotic disease. In: Braunwald E, Zipes DP, Libby P. [eds]. Heart Disease:A Text Book of Cardiovascular Medicine, 6th edn. W.B. Saunders Co.: Philadelphia, PA, 2001, p. 1024.

14. Rao SV, Donahue M, Pi-Sunyer FX, et al. Results of Expert Meetings: Obesity and Cardiovascular Disease. Obesity as a risk factor in coronary artery disease. Am Heart J. 2001 Dec;142(6):1102-7.

15. Eckel RH. Obesity and heart disease: a statement for healthcare professionals from the Nutrition Committee, American Heart Association. Circulation. 1997 Nov 4;96 (9):3248-50.

16. Gaziano JM. Global burden of cardiovascular disease. In: Braunwald E, Zipes DP, Libby P. [eds].
Heart Disease: A Textbookof Cardiovascular Medicine, 6th edn.W.B.Saunders Co.:Philadelphia, PA, 2001,p. 15

17. Eckel RH, Krauss RM. American Heart Association call to action: obesity as a major risk factor for coronary heart disease. AHA Nutrition Committee. Circulation. 1998 Jun 2;97(21):2099-100.

18. Wolf AM, Colditz GA. The cost of obesity: the US perspective. Pharmacoeconomics. 1994;5 (Suppl 1): 347. DOI:10.2165/00019053-199400051-00007

19. Wolf AM, Colditz GA. Current estimates of the economic cost of obesity in the United States. Obes Res. 1998 Mar;6(2):97-106.

20. James PT, Leach R, Kalamara E, et al. The world wide obesity epidemic. Obes Res. 2001 Nov;9 Suppl 4:228S-233S. DOI:10.1038/oby.2001.123

21. World Health Organization. Obesity: Preventing and Managing the Global Epidemic. Report of a WHO consultation of obesity.WHO, Geneva, 3-5 June 1977.

22. Frilander H, Solovieva S, Mutanen P, et al. Role of overweight and obesity in low back disorders among men: a longitudinal study with a life course approach. BMJ Open. 2015 Aug 21;5(8):e007805. doi: 10.1136/ bmjopen- 2015-007805.

23. Shiri R, Karppinen J, Leino-Arjas P, et al. The association between obesity and low back pain: a metaanalysis. Am J Epidemiol. 2010 Jan 15;171(2):135-54. doi: 10.1093/aje/kwp356. Epub 2009 Dec 11.

24. Ezemagu, U.K., C.I.P Anibeze, C.O. Ani and Ossi, G.C. 2016. Correlation of Body Mass Index with Low Back Pain amongst Patients without Injury in a Nigeria Population.Int.J.Curr.Microbiol.App.Sci.5(11):371-378. doi: http://dx.doi.org/10.20546/ ijcmas.2016. 511. 042.

25. Louisa Chou, Sharmayne R.E. Brady, Donna M. Association between obesity and low back pain and disability is affected by mood disorders. 2016 Apr; 95(15): e3367.doi: 10.1097/MD.0000000000003367.

26. Chowdhury D, Sarkar S, Rashid MH et al. Influence of body mass index on low back pain. Mymensingh Med J. 2014 Jan;23(1):125-9.

\section{How to cite this article?}

Reddy D.M, Jagarlamudi P. Observational study to correlate BMI with low back pain in young adults. Surgical Update: Int J surg Orthopedics. 2019;5 (2):100-104.doi:10.17511/ijoso.2019.i02.06. 